\title{
COMPARISON OF PERFORMANCE CHARACTERISTICS OF TWO MALARIA RAPID DIAGNOSTIC TESTS IN DETECTING MALARIA INFECTION AMONG FEBRILE PATIENTS IN URBAN AREA OF LAGOS, NIGERIA
}

\author{
Odeniyi, O. M. ${ }^{1}$, Agomo C. O. ${ }^{2 *}$, Okangba, C. C. ${ }^{3}$, Olaniyan, K. O. ${ }^{4}$, Oyibo, W. A. ${ }^{1}$ \\ ${ }^{1}$ Department of Medical Microbiology and Parasitology, College of Medicine of the University of Lagos, Nigeria. \\ ${ }^{2}$ Department of Medical Laboratory Science, College of Medicine of the University of Lagos, Nigeria. \\ ${ }^{3}$ Department of Medical Microbiology \& Parasitology Benjamin S. Carson School of Medicine Babcock University, \\ Ilisan - Remo, Ogun State. \\ ${ }^{4}$ Department of Product Development and Quality Assurance, Nigeria Natural Medicine Development Agency, Lagos, \\ Nigeria. \\ *Corresponding Author's Email address: coagomo@unilag.edu.ng; Tel: +2348122592251 \\ (Received: $14^{\text {th }}$ May, 2020; Accepted: $16^{\text {th }}$ June, 2020)
}

\section{ABSTRACT}

\begin{abstract}
Antigen-based malaria rapid diagnostic tests (mRDT) play an important role in confirmation of malaria cases in all levels of healthcare in Nigeria because they are fast, easy to perform, and do not require special equipment or electricity. This study aimed at assessing the performance of two mRDTs in detecting histidine-rich protein 2 antigen in blood and urine of persons with uncomplicated falciparum malaria. Malaria parasite microscopy was the malaria diagnosis gold standard in this study. Matched blood and urine samples from 1,026 febrile persons were tested with two commercially available malaria antigen-detecting kits (SD Bioline ${ }^{\circledR}$ and First Response ${ }^{\mathbb{B}}$ ). Based on blood samples, similar malaria positivity rates were obtained by microscopy 181 (17.6\%), SD Bioline 186 (18.1\%) and First Response 183 (17.8\%). Detection of HRP2 antigens in urine was significantly lower than HRP2 detection in blood $(\mathrm{P}<0.001)$ regardless of brand of mRDT used [SD Bioline ${ }^{\circledR}(5.2 \%$ vs $18.1 \%)$ and First Response $^{\circledR}(4.6 \%$ vs $17.8 \%)$ ]. The performance characteristics of SD Bioline ${ }^{\circledR}$ and First Response ${ }^{\circledR}$ using blood samples were similar ( $\mathrm{P}>0.05$ ): sensitivity $96.7 \%$ vs $95.0 \%$; specificity $98.7 \%$ vs $98.7 \%$, Positive Predictive Value (PPV) $92.5 \%$ vs 94\% and Negative Predictive Value (NPV) 99.3\% vs $86.4 \%$. SD Bioline ${ }^{\circledR}$ and First Response $^{\circledR}$ had low sensitivities $(27.1 \%$ and $24.3 \%$ respectively) in detecting HRP2 in urine. Detection of HRP2 in urine and blood by the two kits was not dependent on the level of parasitaemia. The performance of the two brands of mRDTs in detecting HRP2 in whole blood and urine were similar $(\mathrm{P}>0.05)$. The two kits serve as good alternatives to malaria microscopy. The high NPV of both kits with urine specimen indicates that urine has the potential to be used for malaria but is not currently recommended to be used on blood-based malaria test kits.
\end{abstract}

Keywords: Histidine Rich Protein 2, Malaria Rapid Diagnostic Test, Performance characteristics, Urine.

\section{INTRODUCTION}

Malaria is caused by infection of red blood cells with protozoan parasites belonging to the genus Plasmodium transmitted by female Anopheles' mosquito (Regev-Rudzki et al., 2013). Of the five species of Plasmodium that infect man (P. falciparum, $P$. vivax, $P$. ovale, $P$. malariae and $P$. knowlesi), $P$. falciparum is the most prevalent in Nigeria, accounting for over $90 \%$ of malaria infections (Federal Ministry of Health, 2015; Bichara et al., 2017). In Nigeria, the burden of malaria is a major contributor to the economic burden of disease in communities where it is endemic and it is responsible for annual economic loss of 132 billion naira (Jimoh et al., 2007; Rumun and Terungwa, 2015). In 2018, Nigeria accounted for $25 \%$ of global malaria cases, with over 56 million cases and 95,000 deaths (WHO, 2019a).
The common symptoms associated with malaria include fever, headache, chills, anorexia, vomiting, malaise and joint pains but these are non-specific as they are also observed in other infectious diseases caused by bacteria and viruses (Rasheed $e t$ al., 2009; Tahita, et al., 2013). Thus, clinical diagnosis of malaria leads to overdiagnosis of malaria in health facilities (Uzochukwu et al., 2009; Oladosu and Oyibo, 2013). The World Health Organization has therefore recommended routine parasite-based confirmation of suspected cases of malaria by either microscopy or mRDT (WHO, 2015). In malaria endemic countries including Nigeria, mRDTs have been deployed by malaria control programmes as a tool for parasite-based diagnosis because they are fast, easy to perform, does not require special equipment or electricity, and can also be carried out by non-specialized 
health care workers.

In Nigeria, it is estimated that $60 \%$ of outpatient visits and 30\% hospitalizations are attributable to malaria (Federal Ministry of Health, 2015). In Nigeria, mRDTs have the capacity to improve the quality of malaria diagnosis in health facilities considering the high number of patients visiting the hospitals for care. High workload negatively affects the quality of malaria diagnosis by microscopy because it is subject to human error due to fatigue compared with mRDTs (Burchett et al., 2017). The mRDTs bridge diagnosis gap in areas where malaria microscopy in not feasible, thereby checkmating the irrational use of antimalarial medicines. It is therefore important that mRDTs perform optimally, in terms of their sensitivity and specificity, to be relied on in health facilities for the rapid diagnosis of malaria.

Malaria antigen-detecting rapid diagnostic tests are based on the principle of immunochromatographic detection of malaria parasite antigen such as histidine-rich protein II (HRP-2) or specific Plasmodium lactate dehydrogenase (pLDH). The HRP-2 antigen is produced only by $P$. falciparum and is produced by all the stages of this malaria parasite species (Hayward et al., 2000; Desakorn, 2005). Histidinerich protein 2 is a soluble protein secreted into the blood stream, and is therefore detectable in an infected person even when parasites are sequestered in capillaries of deep tissues (Rubach et al., 2012). In clinical malaria, patients shed elevated levels of proteins, including Plasmodium falciparum proteins such as HRP-2, in urine in detectable quantities (Genrich, et al.,2007; Ho et al.2014). This study is aimed at evaluating two mRDTs recommended for use in Nigeria in detecting the presence of malaria antigens in blood and urine samples.

\section{MATERIALS AND METHODS \\ Study Site}

Matched blood and urine samples were collected from two study sites in Lagos: a missionary hospital in Amukoko, Ajeromi Ifelodun Local Government Area (LGA) and a secondary public health facility in Surulere LGA. Amukoko is a densely populated urban area of Lagos with population density of 687,316 and human population in Lagos as at 2019 population was estimated to be 13,903,620 (Twumasi et al., 2020). Amukoko is located on the Longitude $\left(6^{\circ} 27^{\prime}\right.$ $\left.52^{\prime \prime} \mathrm{N}\right)$ and Latitude $\left(3^{0} 20^{\prime} 44^{\prime \prime} \mathrm{E}\right)$. It is about $14 \mathrm{~km}$ from Lagos center, it is bounded on the North by Apapa LGA and on the East by Amuwo-Odofin LGA. Amukoko is the $50^{\text {th }}$ community instituted in Ajeromi-Ifelodun LGA of Lagos state. Surulere General Hospital, Randle is located at the Surulere LGA, Lagos on the Longitude $\left(6.5082^{\circ}\right.$ N) and Latitude $\left(3.3574^{\circ} \mathrm{E}\right)$ with an Area of 23kilometer squares and 503,975 inhabitants with a population density of 21,864 inhabitants per square kilometer, (Twumasi et al., 2020).

\section{Study Population}

Febrile patients with axillary temperatures $\geq 37.5^{\circ} \mathrm{C}$ or history of fever in the last 48 hours attending the out-patient clinics of the two clinics and who consented to the study were recruited into the study. Patients who did not meet the inclusion criteria and who had signs suggestive of severe malaria or other severe illness were excluded from the study.

\section{Sample collection}

Matched blood and urine samples were collected from suspected malaria cases. Prior to sampling, the axillary temperature of each patient was measured with the aid of a mercury-type clinical thermometer. The age, sex and history of fever in last 48 hours of study participants were recorded. Two milliliters of venous blood from each patient was collected in EDTA vacutainer for malaria diagnosis and determination of total white blood cell (WBC) count. Urine was collected into a sterile universal container from each of the study participants. Thick and thin blood films made on same slide were stained with 3\% Giemsa stain and examined for the presence of malaria parasites as described by WHO (2010). At the start of each test procedure, individual patient blood samples were thoroughly mixed and tested for malaria antigen (HRP2) reactivity separately with SDBioline and First Response mRDT kits. Positive (200 parasites/ $\mu$ l of blood) and negative malaria parasite control panels were run along with the samples. The laboratory workup was carried out at the International Centre for Malaria Microscopy, College of Medicine, University of Lagos, Idi Araba, a WHO Quality Assurance Centre for 
mRDTs and Malaria Microscopy.

\section{Ethical consideration}

The study was approved by the Health Research Ethics Committee of the College of Medicine, University of Lagos, Lagos, Nigeria. All the study participants consented to the study before they were recruited into the study.

\section{Data analysis}

The performance characteristics of the mRDTs were determined by calculating sensitivity, specificity, positive and negative predictive values (Kyabayinze et al., 2008).

Sensitivity $=\frac{\text { True positive }}{\text { True positive }+ \text { False Negative }} \times 100$

Specificity $=\frac{\text { True Negative }}{\text { True Negative }+ \text { False Positive }} \times 100$

Positive Predictive Value (PPV) $=$

$\frac{\text { True positive }}{\text { True positive }+ \text { False Negative }} \times 100$

Negative Predictive Value (NPV) =

$\frac{\text { True Negative }}{\text { True Negative }+ \text { False Positive }} \times 100$
Personal identifiers were removed from the data before entry into a Microsoft Excel and replaced with codes. Access to study data was limited to the investigators. Data were analyzed using EPI INFO version 3.5.1. Proportions were compared using chi square. P-values less than 0.05 were considered significant at $95 \%$ confidence interval.

\section{RESULTS}

\section{Socio-demographic characteristics of study participants}

A total of 1,026 participants were enrolled into this study. There were more females 624 (60.8\%) than males $402(39.2 \%)$. The mean age of the study participants was $25.5 \pm 16.7$ years. Most of the participants were aged 20-29 years 271(26.4\%), followed by those aged 30-39 years, $164(16.0 \%)$. The least age group was children aged 5-9 years, $81(7.9 \%)$.

Table 1: Baseline Demographic Characteristics of Study Participants

\begin{tabular}{cc}
\hline Character & $\mathbf{N ~ ( \% )}$ \\
\hline $\begin{array}{c}\text { Number of participants } \\
\text { Age (years) }\end{array}$ & 1026 \\
Mean \pm SD & $25.5 \pm 16.7$ \\
$<5$ & $144(14.0)$ \\
$5-9$ & $81(7.9)$ \\
$10-19$ & $138(13.5)$ \\
$20-29$ & $271(26.4)$ \\
$30-39$ & $164(16.0)$ \\
$40-49$ & $119(11.6)$ \\
$\geq 50$ & $109(10.6)$ \\
Gender & \\
Male & $402(39.2)$ \\
Female & $624(60.8)$ \\
\hline
\end{tabular}

Malaria prevalence in the study population

Malaria prevalence varied widely based on type of sample analyzed regardless of the type of diagnostic method. Malaria prevalence based on microscopy, the gold standard, was $17.6 \%$. The prevalence based on SD-Bioline and First
Response malaria antigen test kits using blood specimen were $18.1 \%$ and $17.8 \%$ respectively. Lower prevalence rates were obtained using urine as specimen for malaria diagnosis on blood-based mRDT [SD Bioline 5.2\%; First Response 4.6\%] compared to using blood samples. 
Table 2: Malaria Prevalence by Microscopy and the two mRDTs

\begin{tabular}{lcc}
\hline Malaria test & Specimen Used & Malaria Prevalence (\%) \\
\hline Microscopy & Blood & $181(17.6)$ \\
SD-Bioline mRDT & Blood & $186(18.1)$ \\
First Response mRDT & Blood & $183(17.8)$ \\
SD-Bioline mRDT & Urine & $53(5.2)$ \\
First Response mRDT & Urine & $47(4.6)$ \\
\hline
\end{tabular}

\section{Kit Sensitivity and specificity}

The sensitivity of SD Bioline and First Response malaria test kits using whole blood as diagnostic specimen were $96.7 \%$ and $95.0 \%$ respectively while their specificity was the same, $98.7 \%$.

Table 3: Performance of SD Bioline and First Response using Blood Sample

\begin{tabular}{ccccccccc}
\hline & & \multicolumn{3}{c}{ Microscopy } & \multicolumn{3}{c}{ Performance characteristics } \\
Kit type & & Neg & Pos & Total & Sensitivity & Specificity & PPV & NPV \\
$(\%)$ & $(\%)$ & $(\%)$ & $(\%)$ \\
\hline SD & Neg & 834 & 6 & 840 & 96.7 & 98.7 & 94.1 & 99.3 \\
Bioline & Pos & 11 & 175 & 186 & & & & \\
& Total & 845 & 181 & 1026 & & & & \\
\hline \multirow{2}{*}{ First } & Neg & 834 & 9 & 843 & 95 & 98.7 & 94 & \\
Response & Pos & 11 & 172 & 183 & & & & \\
& Total & 845 & 181 & 1026 & & & & \\
\hline
\end{tabular}

The sensitivity for SD- Bioline and First Response and 24.3\% respectively while their specificity was using urine as diagnostic specimen were $27.1 \% \quad 99.5 \%$ and $99.6 \%$ respectively.

Table 4: Performance of SD Bioline and First response Using Urine Sample

\begin{tabular}{ccrrrrrrr}
\hline & & \multicolumn{3}{c}{ Microscopy } & \multicolumn{3}{c}{ Performance characteristics } \\
Kit type & & Neg & Pos & Total & $\begin{array}{c}\text { Sensitivity } \\
\text { S\%) }\end{array}$ & $\begin{array}{c}\text { Specificity } \\
\mathbf{( \% )}\end{array}$ & $\begin{array}{c}\text { PPV } \\
\mathbf{( \% )}\end{array}$ & $\begin{array}{c}\text { NPV } \\
\text { (\%) }\end{array}$ \\
\hline SD & Neg & 841 & 132 & 973 & 27.1 & 99.5 & 92.5 & 86.4 \\
Bioline & Pos & 4 & 49 & 53 & & & & \\
& Total & 845 & 181 & 1026 & & & & \\
\hline \multirow{2}{*}{ First } & Neg & 842 & 137 & 979 & 24.3 & 99.6 & 93.6 & 86 \\
Response & Pos & 3 & 44 & 47 & & & & \\
& Total & 845 & 181 & 1026 & & & & \\
\hline
\end{tabular}

\section{Comparison of kits}

The comparison of the performance characteristics of the two brands of mRDT showed that the two mRDT brands were similar ( $\mathrm{P}$ $=0.05)$ in terms of sensitivity, specificity, PPV and NPV. 
Table 5: Comparison of the performance of SD Bioline and First Response in detecting HRP2 antigen from Blood and Urine

\begin{tabular}{|c|c|c|c|c|c|c|}
\hline \multirow[b]{2}{*}{ Performance } & \multicolumn{2}{|c|}{ Blood } & \multicolumn{4}{|c|}{ Urine } \\
\hline & $\begin{array}{c}\text { SD } \\
\text { Bioline }\end{array}$ & $\begin{array}{c}\text { First } \\
\text { Response }\end{array}$ & $\mathrm{P}$ & SD Bioline & $\begin{array}{c}\text { First } \\
\text { Response }\end{array}$ & $\mathrm{P}$ \\
\hline Sensitivity $(\%)$ & 96.7 & 95 & 0.429 & 27.1 & 24.3 & 0.548 \\
\hline Specificity $(\%)$ & 98.7 & 98.7 & - & 99.5 & 99.6 & 1.00 \\
\hline PPV (\%) & 94.1 & 94 & 0.967 & 92.5 & 93.6 & 0.869 \\
\hline NPV $(\%)$ & 99.3 & 98.9 & 0.441 & 86.4 & 86 & 0.784 \\
\hline
\end{tabular}

However, there were significant differences values of specificity of SD Bioline obtained from $(\mathrm{P}<0.001)$ when the sensitivity and NPV values of analyzing blood and urine were similar $(\mathrm{p}=0.082)$ the two mRDT brands obtained from analyzing but this was not the case with First Response ( $\mathrm{p}=$ blood and urine specimen were compared. The 0.044).

Table 6: Comparison of HRP-2 Detection in Blood and Urine using SD Bioline and First Response

\begin{tabular}{lcccccc}
\hline \multirow{2}{*}{ Performance } & \multicolumn{3}{c}{ SD Bioline } & \multicolumn{3}{c}{ First Response } \\
& Blood & Urine & $\mathbf{P}$ & Blood & Urine & P \\
\hline Sensitivity (\%) & 96.7 & 27.1 & $<0.001$ & 95 & 24.3 & $<0.001$ \\
Specificity (\%) & 98.7 & 99.5 & 0.082 & 98.7 & 99.6 & 0.044 \\
PPV (\%) & 94.1 & 92.5 & 0.911 & 94 & 93.6 & 0.805 \\
NPV (\%) & 99.3 & 86.4 & $<0.001$ & 98.9 & 86 & $<0.001$ \\
\hline
\end{tabular}

Rapid kits comparison with Gold standard

The detection of HRP2 in parasitized blood or urine specimen by the two brands of mRDT was not dependent on the parasite density. The detection of HRP2 in blood was $>90 \%$ at $1-200$ parasites $/ \mu \mathrm{l}$ of blood and equally have highest detection positivity of malaria antigen at parasitemia range $\geq 500$ parasites/ $\mu$ l of blood. However, the detection of HRP2 in urine were low irrespective of the type of kit used as there are irregularities in the detection positivity of malaria antigen at different ranges of parasite densities

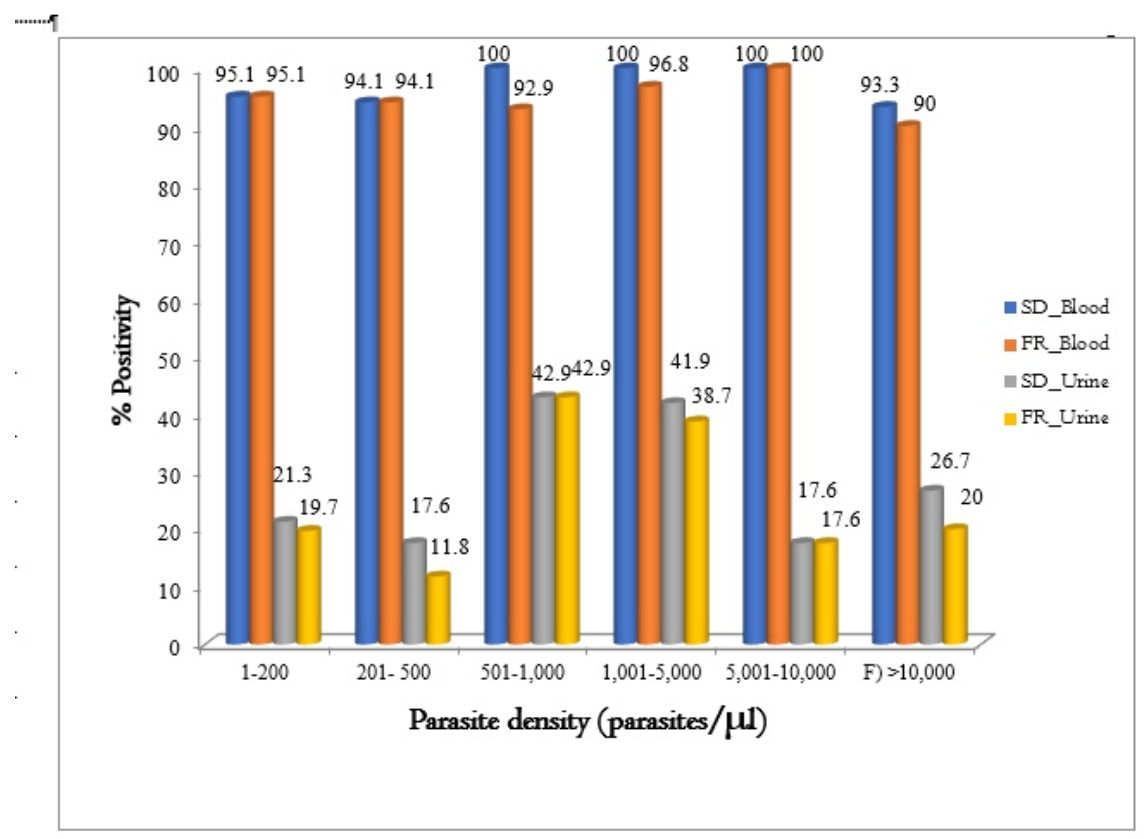

Figure 1: Detection of Plasmodium falciparum HRP2 antigen from blood and urine using mRDT kits based on parasite density 


\section{DISCUSSION}

The prevalence of malaria among febrile patients in this study based on microscopy (parasite density) was $17.6 \%$, however, the prevalence based on the RDTs were similar to the rate determined by microscopy. The prevalence reported in this study was lower than the reports of Oladosu and Oyibo (2013) and Orish et al. (2016) who reported $20.7 \%$ and $21.3 \%$ prevalence respectively, among febrile children aged 0-12 years. The low prevalence might be as a result of scale up of malaria intervention programmes in Lagos state in the last 5 years. Another possible reason could be the difference in the study populations. In our study, study participants included children and adults while Oladosu and Oyibo (2013) and Orish et al. (2016) worked with children $\leq 12$ years. The inclusion of adults who have been noted to have considerably lower malaria prevalence than children could have brought down the prevalence reported in this study (Aina et al., 2013; Olukosi et al., 2018).

The use of other body fluids other than blood for the detection of malaria parasites would bring a great relief to communities with blood taboos (Mharakurwa et al., 2006). Other workers have experimented with detection of malaria infection with other body fluids. Anchinmane and Shedge (2016) detected malaria antigens in urine using malaria RDTs. Mharakurwa et al. (2006) reported that $P$. falciparum infection can be detected in urine and saliva using polymerase chain reaction method. Katzin et al. (1991) detected malarial antigens in urine by Western blot method. In this study, HRP2 antigens were detected in urine of persons infected with falciparum malaria, although the positivity rate was much lower than HRP2 detection in blood, hence, using urine for malaria parasite detection in persons infected with falciparum malaria in place of blood is not recommended.

In this study, the performance characteristics of SD-Bioline and First Response in malaria diagnosis were similar regardless of the specimen used. This finding is consistent with the prequalification assessment of malaria test kits conducted by the Federal Ministry of Health, which led to their recommendation for use in routine diagnosis of malaria in Nigeria (Federal
Ministry of Health, 2015). The significantly lower sensitivity of blood-based malaria test kits when urine is used has also been reported by other workers. Genton et al. (1998) reported 84\% sensitivity for a blood based mRDT (ParaSight ${ }^{\circledR}-\mathrm{F}$ test) with blood and $26 \%$ with urine as specimen for malaria testing. Similar findings were also reported by Buppan et al. (2010), Anchinmane and Shedge (2016) and Samal et al. (2017). The lower sensitivity might be due to the degradation or proteolytic cleavage of HRP2 excreted in urine (Ehrich et al., 1985; Mharakurwa et al., 2006). The positive predictive value of the two kits were similar regardless of the specimen used. A high PPV of $>90 \%$ is an indication that urine has good potentials of being a specimen for malaria diagnosis. Similar findings were also reported by Buppan et al., (2010) and Samal et al., (2017). An improvement in the sensitivity of the kits may enable low levels of malaria antigen found in urine to be detected (Genton et al., 1998).

The high specificity of the kits using blood specimen observed in this study was similar to the reports of other workers who reported high specificity of over $97 \%$ for SD Bioline (Tadese et al., 2016; Azazy et al., 2018) and over for 93\% for First Response (Ghouth et al., 2012; Ayogu et al., 2016). This is one of the strong points of mRDTs that led to recommendation of the use of mRDT in malaria endemic areas for routine malaria diagnosis. As malaria prevalence drops locally and globally (WHO, 2019a), the contribution of malaria to number of febrile cases also drops. It is therefore important to exclude malaria from other febrile illnesses in order to improve the rational use of antimalarial medicines.

In this study, a linear relationship between malaria positivity and level of parasitaemia was not observed in blood and urine specimen of parasitized individuals. The secretion of HRP2 antigen is not uniform across the different strains of P. falciparum. Some strains of P. falciparum do not express HRP2 protein and may cause falsenegative results with HRP2-based mRDTs (WHO, 2019b). Occasionally, high levels of HRP2 are expressed during early stage of asexual cycle alongside a fast rise in parasite concentration at the ring stage, then a slower buildup at both trophozoites and schizonts stages (Howard et al., 
1986 and Desakorn, 2005). Immature gametocytes express HRP2 antigens much more than mature gametocytes (Hayward et al., 2000; Zanghi et al., 2018). The sensitivity of HRP2based kits is also improved by cross-reaction with HRP3 antigen, an antigen homologous to HRP2 (Beshir et al., 2017). This property may be responsible for detection of malaria at low parasitaemia.

\section{CONCLUSION}

SD-Bioline and First Response malaria antigen test kits can serve as alternatives to malaria microscopy. The performance characteristics of the two mRDTs in the detection of HRP2 antigens in blood and urine were similar. The high negative predictive value of both kits when urine specimen was used indicates that urine has the potential to be a diagnostic specimen for malaria if there is the possibility of increasing the sensitivity of these tools to detect low levels of HRP2 in urine. The detection of HRP2 antigen was not dependent on the level of parasitaemia.

\section{CONFLICT OF INTEREST}

The authors declare no conflict of interest.

\section{REFERENCES}

Aina, O.O., Agomo, C.O., Olukosi, Y.A., Okoh, H.I., Iwalokun, B.A., Egbuna, K.N and Agomo, P.U. 2013. Malariometric Survey of Ibeshe Community in Ikorodu, Lagos State: Dry Season. Malaria Research and Treatment, 2013, 487250.

Anchinmane, V T. and Shedge, R.T. 2016. Detection of malaria parasite in urine of malaria patients: a future diagnostic approach. International Journal of Research in Medical Sciences. 4(5),17021705.

Ayogu, E.E., Ukwe C.V. and Nna, E.O.2016. Assessing the reliability of microscopy and rapid diagnostic tests in malaria diagnosis in areas with varying parasite density among older children and adult patients in Nigeria. Journal of Postgraduate Medicine 62(3), 150-6.

Azazy, A.A., Alhawery, A.J., Abdul-Ghani R., Alharbi R.A. and Almalki, S.S.R. 2018. Evaluation of Rapid PfHRP-2/pLDHbased Tests in Diagnosing Microscopy-
Confirmed Falciparum Malaria in Hodeidah Governorate, Yemen. Acta Tropica 178, 252-257

Beshir, K.B., Sepulveda, N. Bharmal, J. Robinson, A., Mwanguzi, J., Busula, A.O., de Boer, J.G., Sutherland, C., Cunningham, J. and Hopkins, H. 2017. Plasmodium falciparum parasites with histidine-rich protein 2 (pfhrp2) and pfhrp3 gene deletions in two endemic regions of Kenya. Scientific Reports 7(1), 14718.

Bichara, C., Flahaut, P., Costa, D., Bienvenu, A., Picot, S. and Gargala, G. 2017. Cryptic Plasmodium ovale concurrent with mixed Plasmodium falciparum and Plasmodium malariae infection in two children from Central African Republic. Malaria Journal 16,339.

Buppan, P., Putaporntip, C., Pattanawong, U., Seethamchai, S. and Jongwutiwes, S. 2010. Comparative detection of Plasmodium vivax and Plasmodium falciparum DNA in saliva and urine samples from symptomatic malaria patients in a low endemic area. Malaria Journal 9, 72.

Burchett, H.E.D., Leurent, B., Baiden, F., Baltzell, K., Björkman, A., Bruxvoort, K., Clarke, S., DiLiberto, D., Elfving, K., Goodman, C., Hopkins, H., Lal, S., Liverani, M., Magnussen, P., Mårtensson, A., Mbacham, W., Mbonye, A., Onwujekwe, O., Allen D.R., Shakely, D., Staedke, S., Vestergaard, L.S., Whitty, C.J.M., Wiseman, V. and Chandler, C.I.R. 2017. Improving prescribing practices with rapid diagnostic tests (RDTs): synthesis of 10 studies to explore reasons for variation in malaria RDT uptake and adherence. British Medical Journal Open. 7(3): e012973.

Desakorn, V. 2005. Stage-dependent production and release of histidine-rich protein 2 by Plasmodium falciparum. Transactions of Royal Society Tropical Medicine and Hygiene. 99, 517-524.

Ehrich, J.H. and Hortsmann, R.D. 1985. The Origin of proteinuria in human malaria. Tropical Medical Parasitology. 36(1), 39-42.

Federal Ministry of Health 2015. National Antimalarial Treatment Policy. FMOH, 
National Malaria and Vector Control Division, Abuja, Nigeria.

Genrich, G. L., Guarner J., Paddock, C.D., Shieh, W.J., Greer, P. W., Barnwell, J.W and Zaki, S.R. 2007. Fatal malaria infection in travelers: novel immunohistochemical assays for the detection of Plasmodium falciparum in tissues and implications for pathogenesis. American Journal of Tropical Medicine and Hygiene, 76(2):251-259.

Genton, B., Paget, S., Beck, H.P., Gibson, N. and Hii, J. 1998. Diagnosis of Plasmodium falciparum infection using ParaSight ${ }^{\circledR}-\mathrm{F}$ test in blood and urine of Papua New Guinean children. Southeast Asian Journal of Tropical Medicine and Public Health. 29(1), 35-40.

Ghouth, A.S.B., Nasseb F.M. and Al-Kaldy K.H. 2012. The accuracy of the first response histidine-rich protein-2 rapid diagnostic test compared with malaria microscopy for guiding field treatment in an outbreak of falciparum malaria. Tropical Parasitology. 2(1), 35-7.

Hayward, R.E., Sullivan, D.J. and Day, K.P. 2000. Plasmodium falciparum: histidine-rich protein II is expressed during gametocyte development. Experimental Parasitology 96(3), 139-146.

Ho, M.F., Baker, J., Lee, N., Luchavez, J., Ariey, F., Nhem, S., Oyibo, W., Bell, D., González, I., Chiodini, P., Gatton, M. L., Cheng, Q., and McCarthy, J.S. 2014. Circulating Antibodies Against Plasmodium Falciparum Histidine-Rich Proteins 2 Interfere with Antigen Detection by Rapid Diagnostic Tests. Malaria Journal 13, 480 .

Howard, R.J., Uni, S., Aikawa, M., Aley, S.B., Leech, J.H., Lew. A.M., Wellems, T.E., Rener, J. and Taylor, D.W. 1986. Secretion of a malarial histidine-rich protein (Pf HRP II) from Plasmodium falciparuminfected erythrocytes. Journal of Cell Biology. 103(4), 1269-1277.

Jimoh, A., Sofola, O., Petu, A. and Okorosobo, T. 2007. Quantifying the Economic Burden of Malaria in Nigeria Using the Willingness to Pay Approach. Cost Effectiveness and Resource Allocation. 5,
6.

Katzin, A.M., Kimura, E.S., Alexandre, C. and Ramos, A.M. 1991. Detection of antigens in urine of patients with acute falciparum and vivax malaria Infections. American Journal Tropical Medicine and Hygiene. 45(4), 453-62.

Kyabayinze, D.J., Tibenderana, J.K., Odong, G.W., Rwakimari, J.B. and Counihan, H. 2008. Operational accuracy and comparative persistent antigenicity of HRP2 rapid diagnostic tests for Plasmodium falciparum malaria in a hyperendemic region of Uganda. Malaria Journal 7,221.

Mharakurwa, S., Simoloka, C., Thuma, P.E., Shiff, C.J. and Sullivan, D.J. 2006. PCR detection of Plasmodium falciparum in human urine and saliva samples. Malaria Journal 5, 103.

Oladosu, O. O. and Oyibo, W. A. 2013. Overdiagnosis and overtreatment of malaria in children that presented with fever in Lagos, Nigeria. ISRN Infectious Diseases 914675,6 .

Olukosi, A.Y., Agomo, C.O., Aina, O.O., Akindele, S.K., Okoh, H.O., Brai, B.C and Awolola, S. 2018. Prevalence of malaria and anaemia during the dry season in North Central and South Western Nigeria. Journal of Parasitology and Vector Biology. 10(1), 8-18.

Orish, V. N., Ansong, J.Y., Onyeabor, O. S., Sanyaolu, A.O., Oyibo, W.A and Iriemenam, N. C. 2016. Overdiagnosis and overtreatment of malaria in children in a secondary healthcare center in Sekondi-Takoradi, Ghana. Tropical Doctor 46(4), 191-198.

Rasheed, A., Saheed, S. and Khan, S.A. 2009. Clinical and laboratory findings in acute malaria caused by various Plasmodium species. Journal of Pakistan Medical Association. 59(4), 220-223.

Regev-Rudzki, N., Wilson, D.W., Carvalho, T.G., Sisquella, X., Coleman, B.M., Rug, M., Bursac, D., Angrisano, F., Gee, NM., Hill, A.F., Baum, J. and Cowman, A.F. 2013. Cell-cell communication between malariainfected red blood cells via exosome-like vesicles. Cell 153(5), 1120-1133.

Rubach, M.P., Mukemba, J., Florence, S., John, B., 
Crookston, B., Lopansri, B. K., Yeo, T. W., Piera, K. A., Alder, S.C., Weinberg, J.B., Anstey, N.M., Granger, D.L., and Mwaikambo, E.D. 2012. Plasma Plasmodium falciparum histidine-rich protein-2 concentrations are associated with malaria severity and mortality in Tanzanian children PLoS One. 7(5), e35985.

Rumun, A.J. and Terungwa, M. 2015. Perception of malaria and treatment seeking behavior among rural dwellers in Nigeria. Global Journal of Interdisciplinary Social Sciences. 4(2), 1-6.

Samal, A.G., Behera, P.K., Mohanty, A.K., Satpathi, S., Kumar, A., Panda, R.R., Minz, A.M., Mohanty, S., Samal, A. and Van Der Pluijm, R.W. 2017. The sensitivity and specificity of a urine based Rapid Diagnostic Test for the diagnosis of Plasmodium falciparum in a malaria endemic area in Odisha, India. Pathogens and Global Health.111(7), 383-387.

Tadesse, E., Workalemahu, B, and Shimelis T 2016. Diagnostic performance evaluation of the SD Bioline malaria antigen Ag $\mathrm{Pf} /$ pan test $(05 \mathrm{fk} 60)$ in a malaria endemic area of Southern Ethiopia. Revista do Instituto de Medicina Tropical de Sao Paulo 58:59.

Tahita, M.C., Tinto, H., Menten, J., Ouedraogo, JB., Guiguemde, R.T., van Geertruyden, J.P., Erhart, A. and D'Alessandro U. 2013. Clinical signs and symptoms cannot reliably predict Plasmodium falciparum malaria infection in pregnant women living in an area of high seasonal transmission. Malaria Journal 12, 464.

Twumasi, Y.A., Merem, E.C., Namwamba, J.B.,
Mwakimi, O.S., Silva, T.A., Abdollahi, K., Okwemba, R., Lukongo, B., Akinrinwoye, C.O., Tate, J. and LaCour-Conant, K. 2020. Degradation of Urban Green Spaces in Lagos, Nigeria: Evidence from Satellite and Demographic Data. Advances in Remote Sensing. 9(1), 32-52.

Uzochukwu, B.S.C., Obikeze, E.N., Onwujekwe, O.E., Onoka, C.A. and Griffiths, U.K. 2009. Cost-effectiveness analysis of rapid diagnostic test, microscopy and syndromic approach in the diagnosis of malaria in Nigeria: implications for scaling-up deployment of ACT. Malaria Journal 8, 265.

World Health Organization 2010. Malaria Rapid Diagnostic Test Performance; Results of WHO product testing of malaria RDTs: Round 2 (2009). World Health Organization, Geneva, Switzerland.

World Health Organization 2015. The role of RDTs in Malaria Control. Malaria Microscopy / mRDT. World Health Organization, Geneva, Switzerland.

World Health Organization 2019a. World Malaria Report 2019. World Health Organization, Geneva, Switzerland.

World Health Organization 2019b. False-negative RDT results and implications of new reports of $\mathrm{P}$. falciparum histidine-rich protein $2 / 3$ gene deletions. World Health Organization, Geneva, Switzerland.

Zanghi, G., Vembar, S.S., Baumgarten, S., Ding, S., Guizetti, J., Bryant, J.M., Mattei, D., Jensen A.T.R and Scherf, A. 2018. A specific PfEMP1 is expressed in Plasmodium falciparum sporozoites and plays a role in hepatocyte infection. Cell Reports. 22, 2951-2963. 